\title{
Patterning Corrosion-Susceptible Metallic Alloys for Digital Image Correlation in a
}

\section{Scanning Electron Microscope}

A. Githens ${ }^{a}$, S. Daly ${ }^{b, *}$

${ }^{a}$ Department of Materials Science and Engineering, University of Michigan, 2300 Hayward Street, Ann Arbor, MI 48109, USA

${ }^{\mathrm{b}}$ Department of Mechanical Engineering, UC Santa Barbara, Engineering II, Santa Barbara, CA 93106, USA

\section{Abstract}

We investigate the self-assembly of gold nanoparticles on the surface of magnesium functionalized with 3-(aminopropyl)trimethoxysilane or 3-(mercaptopropyl)trimethoxysilane. These nanoparticles served as a speckle pattern for high magnification deformation tracking via digital image correlation combined with scanning electron microscopy. Controlling the $\mathrm{pH}$ of the gold nanoparticle suspension to a specific basicity passivated corrosion in magnesium and in three of its alloys to enable proper nanoparticle bonding and self-assembly. Magnesium was used as a model material as it is particularly difficult to modify for self-assembly because of its propensity to quickly form a thick oxide, hydroxide, and carbonate layer in the presence of oxygen, water, and carbon dioxide, respectively. Moreover, it corrodes in acidic and slightly basic solutions, further complicating the self-assembly process. Due to these difficulties, the successful self-assembly of nanoparticles on magnesium has not previously been reported, to the best of the authors' knowledge. This technique is potentially amendable to other corrosionsusceptible materials. Gold nanoparticles were self-assembled in a uniformly dispersed random distribution on pure cast magnesium, cast AM60 (Mg-6Al-0.5Mn), rolled WE43 (Mg-4Y3Nd/Gd), and extruded ZE20 (Mg-2Zn-0.2Ce).

Keywords: DIC, digital image correlation, SEM, magnesium, Mg

\footnotetext{
* Corresponding Author: Department of Mechanical Engineering, UCSB, Engineering II, Santa Barbara, CA 931065070, USA, e-mail: samdaly@engineering.ucsb.edu

This is the author manuscript accepted for publication and has undergone full peer review but has not been through the copyediting, typesetting, pagination and proofreading process, which may lead to differences between this version and the Version of Record. Please cite this article as doi: $10.1111 /$ str.12215
} 


\section{Introduction}

The self-assembly of nanoparticles on a variety of surfaces is of interest for numerous electronic, optical, and sensor applications [1]. Nanoparticle arrays are generally used in applications where they are highly ordered [2-7] or non-ordered with controllable density [8-12]. This work reports on the self-assembly of uniformly distributed, non-ordered nanoparticles on magnesium and its alloys for use as a speckle pattern for high magnification digital image correlation. To the best of the authors' knowledge, the successful self-assembly of nanoparticles on magnesium has previously not been reported. Magnesium was used as a model material as it is particularly difficult to modify for self-assembly because of its propensity to quickly form a thick oxide, hydroxide, and carbonate layer in the presence of oxygen, water, and carbon dioxide, respectively. Moreover, it corrodes in acidic and slightly basic solutions, complicating the self-assembly process. Using approaches developed for the self-assembly of nanoparticles on less reactive materials like glass, aluminum oxide, tin oxide, and aluminum alloys $[8,12]$ results in the gold nanoparticle suspension attacking the magnesium surface (Figure 1). The approach described herein is inexpensive, provides a dense coverage of particles, and can be easily scaled by adjusting the size of the nanoparticles.

Gold nanoparticles have been successfully bonded to less-reactive substrates via a silane coupling process $[1,8,12]$. The process includes three main stages: first, the substrate is treated to maximize the number of hydroxyl groups on the surface, usually through oxygen plasma cleaning or a strong alkaline cleaning. Next, a silane with at least one hydrolysable alkoxy group undergoes hydrolysis when mixed with water, and the substrate is immersed in this solution to allow bonding between the silane molecules and the hydroxyl groups on the substrate. In the final step, the substrate is immersed in a citrate-stabilized gold nanoparticle solution, where the particles bond to a functional group on the silane molecule, which can be either an amine functional group for electrostatic bonding or a thiol functional group for chemical bonding. Table 1 lists a summary of this technique for less-reactive substrates, as well as the technique for magnesium for comparison purposes. 


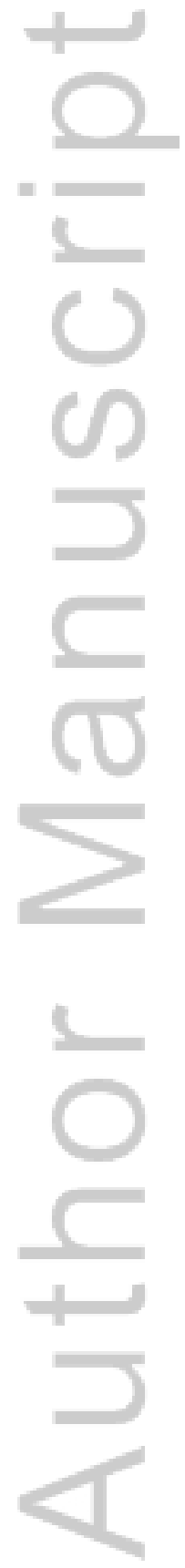

This article is protected by copyright. All rights reserved. 


\begin{tabular}{|c|c|c|c|c|c|}
\hline Material & Glass & $\begin{array}{l}\text { Aluminum } \\
\text { Oxide }\end{array}$ & Tin Oxide & Aluminum & Magnesium \\
\hline $\begin{array}{l}\text { Reference } \\
\text { Source }\end{array}$ & [8] & [8] & {$[8]$} & [12] & this paper \\
\hline $\begin{array}{l}\text { Method to } \\
\text { Increase } \\
\text { Hydroxyl } \\
\text { Group } \\
\text { Concentration } \\
\text { on Substrate }\end{array}$ & $\begin{array}{l}\text { clean in } \\
\text { piranha } \\
\text { solution ( } 4: 1 \\
\text { solution of } \\
\mathrm{H}_{2} \mathrm{SO}_{4} \text { and } \\
\left.30 \% \mathrm{H}_{2} \mathrm{O}_{2}\right)\end{array}$ & $\begin{array}{l}\text { clean in } \\
\text { piranha } \\
\text { solution ( } 4: 1 \\
\text { solution of } \\
\mathrm{H}_{2} \mathrm{SO}_{4} \text { and } \\
\left.30 \% \mathrm{H}_{2} \mathrm{O}_{2}\right)\end{array}$ & $\begin{array}{l}\text { clean in } \\
\text { piranha } \\
\text { solution (4:1 } \\
\text { solution of } \\
\mathrm{H}_{2} \mathrm{SO}_{4} \text { and } \\
\left.30 \% \mathrm{H}_{2} \mathrm{O}_{2}\right)+ \\
\text { immerse in } \\
\mathrm{NaOH}, 5 \mathrm{hr}\end{array}$ & $\begin{array}{l}\text { alkaline } \\
\text { clean in } \\
\mathrm{Na}_{3} \mathrm{PO}_{4} \text { and } \\
\mathrm{Na}_{2} \mathrm{CO}_{3} \text { at } \\
75^{\circ} \mathrm{C}, 60 \mathrm{sec}\end{array}$ & $\begin{array}{l}\text { alkaline } \\
\text { clean in } \\
\mathrm{NaOH} \text { at } \\
50^{\circ} \mathrm{C}, 1 \mathrm{hr}\end{array}$ \\
\hline $\begin{array}{l}\text { Method for } \\
\text { Silanization }\end{array}$ & $\begin{array}{l}\text { immerse in } \\
1: 10 \text { mixture } \\
\text { of APTMS } \\
\text { and methanol } \\
\text { for } 60 \mathrm{hr}\end{array}$ & $\begin{array}{l}\text { immerse in } \\
\text { neat } \\
\text { MPMDMS } \\
\text { for } 3 \mathrm{hr}\end{array}$ & $\begin{array}{l}\text { immerse in } \\
1 \% \\
\text { APMDES for } \\
10-15 \mathrm{~min}\end{array}$ & $\begin{array}{l}\text { immerse in } \\
\text { 1:4 mixture } \\
\text { APTMS/ } \\
\text { MPMDMS } \\
\text { and methanol } \\
\text { for } 24 \mathrm{hr}\end{array}$ & $\begin{array}{l}\text { immerse in } \\
1 \% \text { APTMS } \\
\text { or } 3 \% \\
\text { MPTMS for } \\
5 \text { min }\end{array}$ \\
\hline $\begin{array}{l}\text { Immersion } \\
\text { Time in Gold } \\
\text { Nanoparticle } \\
\text { Suspension }\end{array}$ & $19.5 \mathrm{hr}$ & $12 \mathrm{hr}$ & $8 \mathrm{hr}$ & $24-120 \mathrm{hr}$ & $\begin{array}{l}16-120 \mathrm{hr} \\
\text { (corrosion } \\
\text { occurs if } \\
\text { suspension is } \\
\text { untreated) }\end{array}$ \\
\hline
\end{tabular}

Table 1. Summary of nanoparticle self-assembly steps on less reactive substrates as well as magnesium. Definition: APTMS is 3-(aminopropyl)trimethoxysilane, MPMDMS is 3(mercaptopropyl)methyldimethoxysilane, APMDES is 3(aminopropyl)methyldiethoxysilane, MPTMS is 3-(mercaptopropyl)trimethoxysilane. 
Self-assembly is possible on corrosion-susceptible materials if corrosion can be prevented. The first two steps of the process (increasing the hydroxyl group concentration and silanization) will be different for any material system. Coincidentally, these have already been established for magnesium as they were originally intended to improve the corrosion resistance [13-19]. A primary challenge in this work was to prevent a corrosion reaction between the nanoparticle suspension and magnesium during the long post-silanization soak times required for nanoparticle self-assembly. This soak time was typically on the order of days. It was found that the aforementioned silane layer was not sufficient to prevent corrosion in the gold nanoparticle solution, and self-assembly was therefore not successful without damaging the underlying surface.

In order to prevent corrosion, the nanoparticle suspension was made highly basic by the addition of a strong base, chosen here as sodium hydroxide $(\mathrm{NaOH})$. As indicated by the Pourbaix diagram for magnesium [20], corrosion is passivated under highly basic conditions. This passivation allowed the nanoparticles to bond to the surface without corrosion and aided in proper self-assembly. However, it should be noted that the gold nanoparticles degrade over the course of several hours under environments with a $\mathrm{pH}>12.5$. Degradation was characterized by color fading of the nanoparticle solution, wherein the color effect caused by the nanoparticle suspension diminished as the particles became unstable. This effect was not seen at a $\mathrm{pH} \cong 12$, which was still high enough to significantly inhibit the corrosion of magnesium. Therefore, in the current work, the nanoparticle solution $\mathrm{pH}$ was adjusted using $\mathrm{NaOH}$ to a $\mathrm{pH}$ of 12 .

Once the self-assembly was successful, high magnification deformation tracking using combined digital image correlation (DIC) and scanning electron microscopy (SEM) was possible. DIC has already been combined with SEM to quantify local strain concentrations at the microstructural level for other materials[12, 21-25] . By extending SEM-DIC to magnesium, it is possible to visualize how microstructure is related to deformation phenomena such as slip and twinning. An example is shown in this work. 


\section{Experimental Procedure}

\subsection{Substrate Preparation}

Gold nanoparticles were randomly self-assembled on pure cast magnesium, cast AM60 (Mg-6Al-0.5Mn), rolled WE43 (Mg-4Y-3Nd/Gd), and extruded ZE20 (Mg-2Zn-0.2Ce). All samples were sectioned with a slow speed saw and cold mounted in epoxy. Next, they were metallographically ground with 600, 800, and 1200 standard ANSI grit silicon carbide paper for thirty seconds at each grit, and then polished with a series of $6 \mu \mathrm{m}, 3 \mu \mathrm{m}$, and $1 \mu \mathrm{m}$ water-based diamond suspensions (LapMaster) for five minutes each on Buehler MicroCloth medium-napped pads. Finally, the samples were subjected to a chemo-mechanical polish with a high $\mathrm{pH}$ colloidal alumina/colloidal silica mixture from Buehler (MasterPolish) for four minutes on a Buehler ChemoMet synthetic micro-napped pad, after which they were immediately rinsed with soap and water, rinsed with ethanol, and dried quickly with air. As a final step to improve electron backscatter diffraction (EBSD) analysis for related work, the samples were etched by immersion for 2 seconds in a mixture of $60 \mathrm{~mL}$ ethanol $+20 \mathrm{~mL}$ deionized water $+15 \mathrm{~mL}$ acetic acid +5 $\mathrm{mL}$ nitric acid, followed by a rinse in ethanol and dried with warm air. This final step did not affect nanoparticle self-assembly, and was performed solely to improve EBSD data acquisition. The polished magnesium substrate was then treated to increase the number of hydroxyl groups on the surface in order for the silane to bind correctly. $\mathrm{Mg}(\mathrm{OH})_{2}$ is stable in highly basic environments; thus, a strong alkaline cleaning solution was used to increase the hydroxyl concentration. The samples were immersed in $1 \mathrm{M} \mathrm{NaOH}$ at $50^{\circ} \mathrm{C}$ for 1 hour, rinsed with water for 30s, and then blown dry using compressed air.

\subsection{Silane Hydrolysis \\ 3-(aminopropyl)trimethoxysilane (APTMS) or 3-(mercaptopropyl)trimethoxysilane} (MPTMS) can be used as a silane coupling agent. These silanes undergo hydrolysis when mixed with water, in which alkoxy moieties are converted to hydroxyl groups that allow bonding with the substrate. Over time, these hydrolyzed silane molecules may self-condense and form long 
oligomers in solution, which can lead to particle clumping during nanoparticle self-assembly. The ideal silane contains a maximum number of hydrolyzed molecules with minimal selfcondensation. The rates at which these reactions take place depend on a number of factors, including silane type, silane concentration, water concentration, and $\mathrm{pH}$. Scott et al. characterized the hydrolysis and self-condensation of MPTMS using nuclear magnetic resonance (NMR) and determined that six hours after mixing an acidic 1\% MPTMS solution, hydrolysis is nearly complete without appreciable self-condensation [13]. Ostrovky reported that aminosilanes such as APTMS hydrolyze within minutes in solution and that self-condensation is resisted [17]. An APTMS solution was mixed and allowed to sit for a day to ensure complete hydrolysis, and then reused for as long as 1 month without changes in the final pattern quality.

\subsubsection{Aminosilanes}

A 2.5\% APTMS solution with 50 volume percent water and ethanol as the balance was prepared for deposition on magnesium following Ostrovsky [17]. APTMS was added into a mixture of the water and ethanol at an approximate rate of one pipette drop per second. Ethanol was used as the balance and assisted in dissolving the silane into solution; ethanol was chosen because it does not react with magnesium and is less toxic than methanol.

\subsubsection{Mercaptosilanes}

A 1\% MPTMS solution with 3 volume percent water and ethanol as the balance was prepared for deposition on magnesium, with concentrations determined from Scott et al. [13]. MPTMS was added into a continuously stirred mixture of the water and ethanol at an approximate rate of one pipette drop per second. No additional acid was added to accelerate hydrolysis rates, as it resulted in surface etching. The solution was stirred for 6 hours at a stir rate of 250 RPM.

\subsection{Silane Condensation}

Samples were immersed into a stirred hydrolyzed silane solution for five minutes at a stir rate of 250 RPM. After immersion, they were removed without rinsing and blown dry with air. 
The samples were cured in a dry heat oven at $100^{\circ} \mathrm{C}$ for 1 hour to improve silane adhesion [26, 27], and the inclusion of this step slightly improved particle density.

\subsection{Gold Nanoparticle Synthesis and Application}

Citrate-stabilized gold nanoparticles were synthesized using the Frens technique [28]. Nanoparticles were chosen to be $50 \mathrm{~nm}$ or $100 \mathrm{~nm}$ in diameter, but can be scaled from $15 \mathrm{~nm}$ to $150 \mathrm{~nm}$ in diameter without significantly affecting self-assembly. The $50 \mathrm{~nm}$ nanoparticles were produced by mixing $5 \mathrm{~mL}$ of $1 \mathrm{mM}$ hydrogen tetrachloroaurate with $160 \mathrm{~mL}$ DI water in a continuously stirred Erlenmeyer flask at 380 RPM. The solution was then brought to boiling and $1.75 \mathrm{~mL}$ of $1 \%$ sodium citrate was added. The solution was kept at boiling and continuously stirred for 5 minutes. The solution turned blue after 30 seconds, then a deep red that faded to a wine-red color in approximately two minutes. The $100 \mathrm{~nm}$ nanoparticles were produced by mixing $5 \mathrm{~mL}$ of $1 \mathrm{mM}$ hydrogen tetrachloroaurate with $200 \mathrm{~mL}$ DI water in a continuously stirred Erlenmeyer flask at 380 RPM. The solution was then brought to boiling and $1.75 \mathrm{~mL}$ of $1 \%$ sodium citrate was added. The solution was kept at boiling and continuously stirred for 30 minutes. The solution turned blue after 60 seconds, then gradually changed to a red-orange color. The particles were cooled to room temperature and stored in brown glassware out of light to prevent decomposition.

To inhibit the corrosion of magnesium from the gold nanoparticles, $1 \mathrm{~mL}$ of $0.1 \mathrm{M} \mathrm{NaOH}$ was added to $10 \mathrm{~mL}$ of the nanoparticle suspension. All glassware was thoroughly cleaned beforehand to prevent nanoparticle decomposition. If the nanoparticle suspension darkened, changed color, or became transparent over time, this indicated particle decomposition and the solution was discarded. The silanized magnesium was immersed in the nanoparticles with the surface upon which self-assembly was desired facing up for sixteen hours. The sample was then rinsed with DI water and dried with compressed air. The resulting nanoparticle array was then imaged using scanning electron microscopy to confirm successful self-assembly. All images were taking using a Tescan Mira 3 SEM with a $15 \mathrm{kV}$ accelerating voltage, $20 \mathrm{~mm}$ working 
distance, and $8 \mathrm{~nm}$ spot size. To increase the density of self-assembly, the samples could be reimmersed in the nanoparticle solution for an additional time of up to 120 hours total from initial immersion.

\subsection{In-Situ Mechanical Testing of WE43}

An example of surface strain measurement is demonstrated on the as-received WE43 hotrolled plate. Heated treated specimen blanks were machined using wire electro-discharge machining (EDM) to produce flat dogbone-shaped micro-tensile specimens. The sample was designed so that the tensile loading direction was parallel to the RD. The gage length was 18 $\mathrm{mm}$, sample thickness was $2 \mathrm{~mm}$, and gage section width was $4.5 \mathrm{~mm}$. The sample was first polished and etched using the same method above.

Electron backscatter diffraction (EBSD) was used to measure grain orientation and identify grain boundaries. EBSD was taken using TSL OIM software on a Tescan Mira3 SEM. The accelerating voltage was $30 \mathrm{kV}$, the working distance was $18 \mathrm{~mm}$, and the spot size was 61 nm.

The tensile specimens were pulled in tension to failure along the rolling direction under displacement control at an approximate strain rate of $10^{-4} \mathrm{~s}^{-1}$. SEM micrographs were taken during the tensile test at various stages of plastic deformation for later correlation and displacement calculation. The displacement was stopped at chosen strain intervals to take images.

\section{Results}

\subsection{Nanoparticle Self-Assembly}

As discussed in the introduction, the gold nanoparticle suspension can corrode the silanefunctionalized magnesium and cause cracks and voids on the surface (Figure 1), which can affect the structural integrity of the magnesium. Self-assembly occurs for all $\mathrm{pH}$ levels, but the corrosion disappears at a $\mathrm{pH}$ of 10 or higher, in correspondence with the Pourbaix diagram for 
magnesium. Interestingly, the self-assembly process is not significantly affected by $\mathrm{pH}$, as evidenced in Figure 1. The driving mechanism for self-assembly on APTMS functionalized magnesium is an electrostatic attraction between the negatively charged citrate groups that stabilize the gold nanoparticles and the positively charged amine groups on the silane. Once the isoelectric point of the amine group is reached $(\sim \mathrm{pH}=9)$, the charge becomes negative and would lead one to believe that no self-assembly would take place due to the missing driving force. However, self-assembly of the particles still occurs. It is unknown why the kinetics are seemingly unaffected by increasing the $\mathrm{pH}$ past the isoelectric point of the amine group.

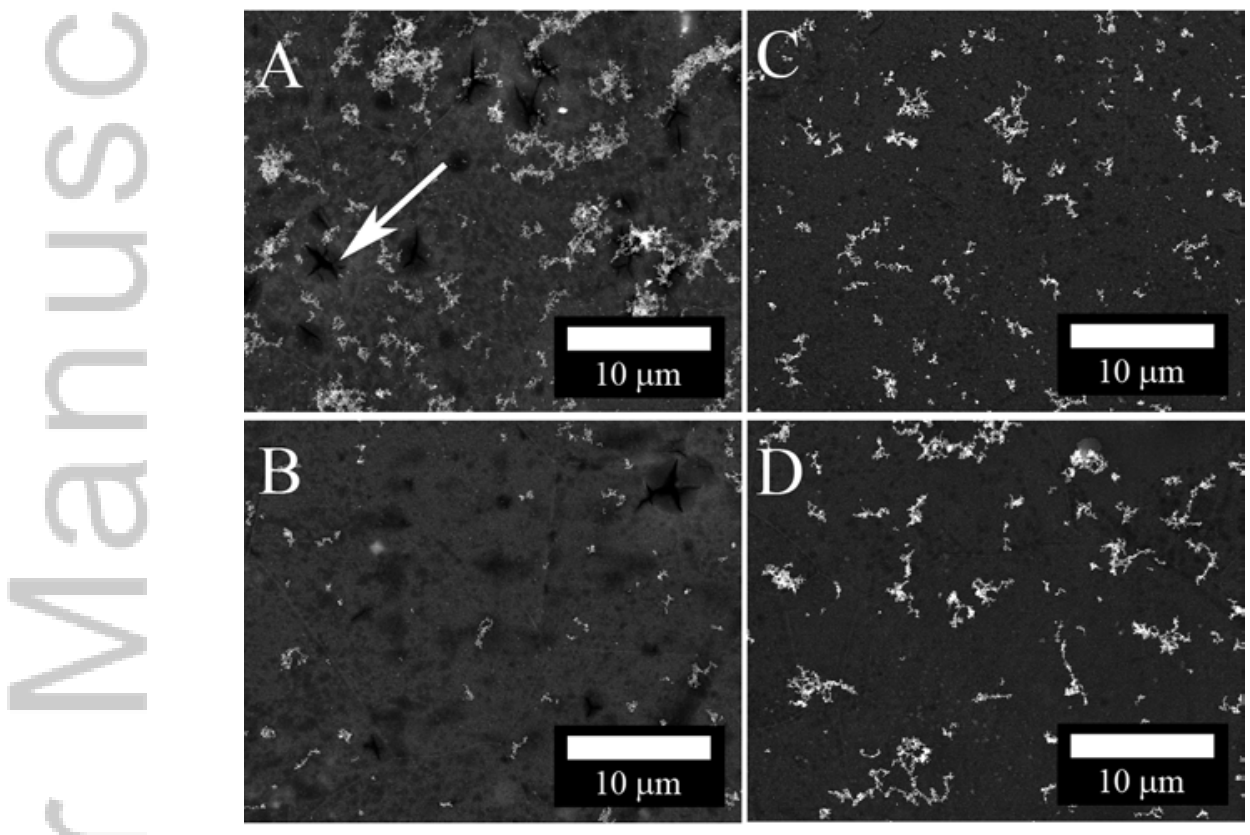

Figure 1. Incomplete self-assembly of $50 \mathrm{~nm}$ gold nanoparticles on APTMS functionalized WE43 magnesium alloy after a 16 hour immersion. The $\mathbf{p H}$ of the gold nanoparticle suspension was modified by adding $\mathrm{NaOH}$ to $\mathrm{A}$ ) $\mathrm{pH}=6$ (native $\mathrm{pH}$ of the suspension), $\mathrm{B}$ ) $\mathrm{pH}=8, \mathrm{C}$ ) $\mathrm{pH}=10$, and D) $\mathbf{p H}=12$. Incomplete assembly is shown here to illustrate the effect of the gold nanoparticle suspension on the magnesium surface, which cannot be seen under a dense nanoparticle array. Figures $A$ and $B$ exhibit corrosion pitting indicated by the white arrow, while figures $C$ and $D$ show that this corrosion is passivated while allowing for gold nanoparticle attachment.

The successful self-assembly of non-ordered nanoparticle distributions on magnesium and three of its alloys is shown in Figure 2. Figure 3 shows the successful self-assembly of two 
different particle sizes. APTMS and MPTMS yielded similar results, although final soak times in the nanoparticle solution varied between alloy systems and between tests. In general, shorter soak times were needed for pure magnesium and longer soak times were needed for its alloys. APTMS and MPTMS were found to yield comparable results; APTMS was preferred because it was more convenient. The MPTMS solution must be stirred for six hours and then disposed of immediately after use, whereas the APTMS solution could be reused for up to one month.
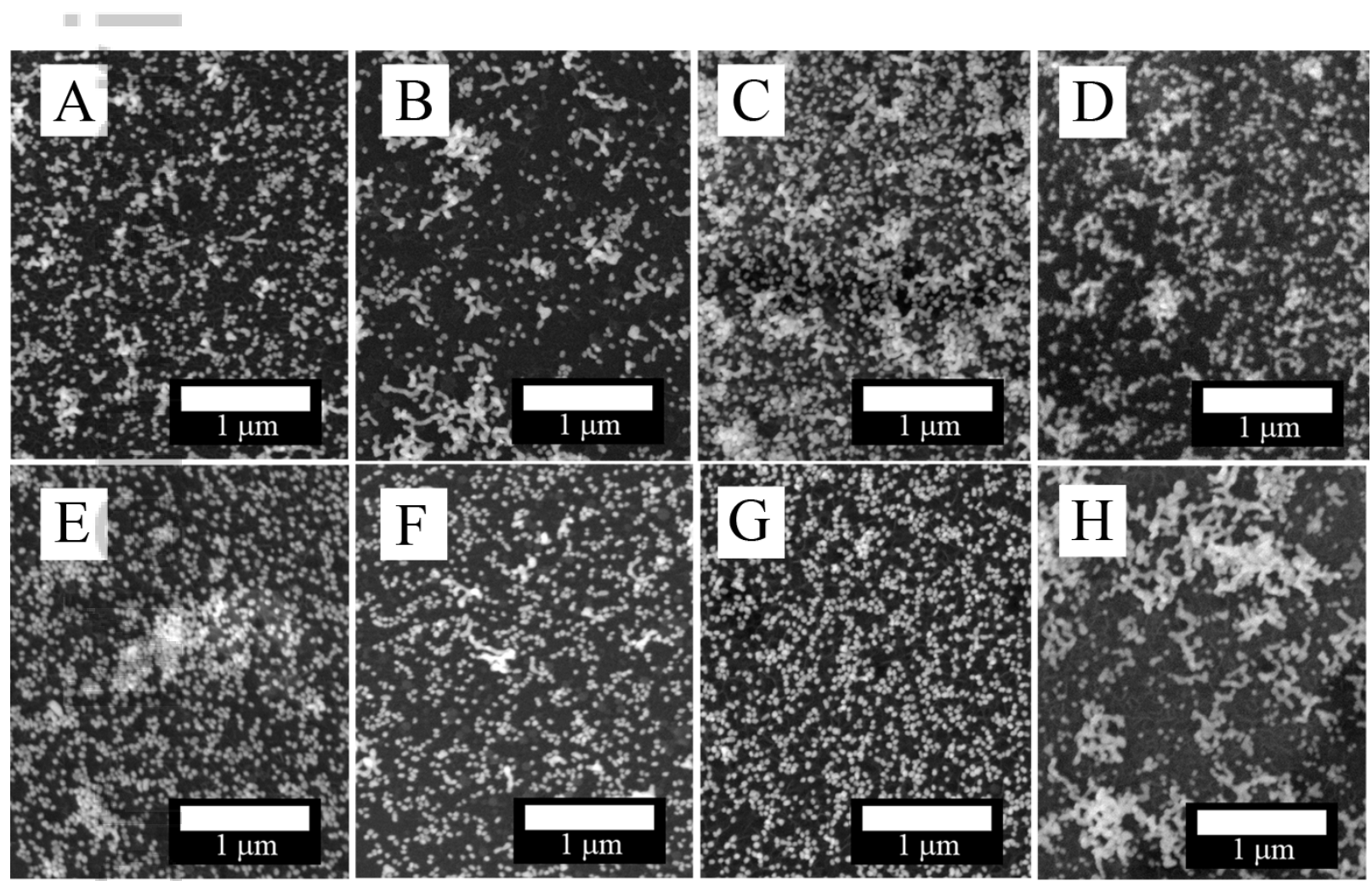

Figure 2. Uniform non-ordered distribution of $50 \mathrm{~nm}$ gold nanoparticles on various magnesium alloys. The top row includes APTMS treated samples of A) pure magnesium immersed in the basic gold nanoparticle solution for 16 hours, B) AM60 immersed for 120 hours, C) WE43 immersed for 120 hours, and D) ZE20 immersed for 40 hours. The bottom row includes MPTMS treated samples of $E$ ) pure magnesium immersed in the basic gold nanoparticle solution for 16 hours, F) AM60 immersed for 96 hours, G) WE43 immersed for 16 hours, and H) ZE20 immersed for 96 hours. 


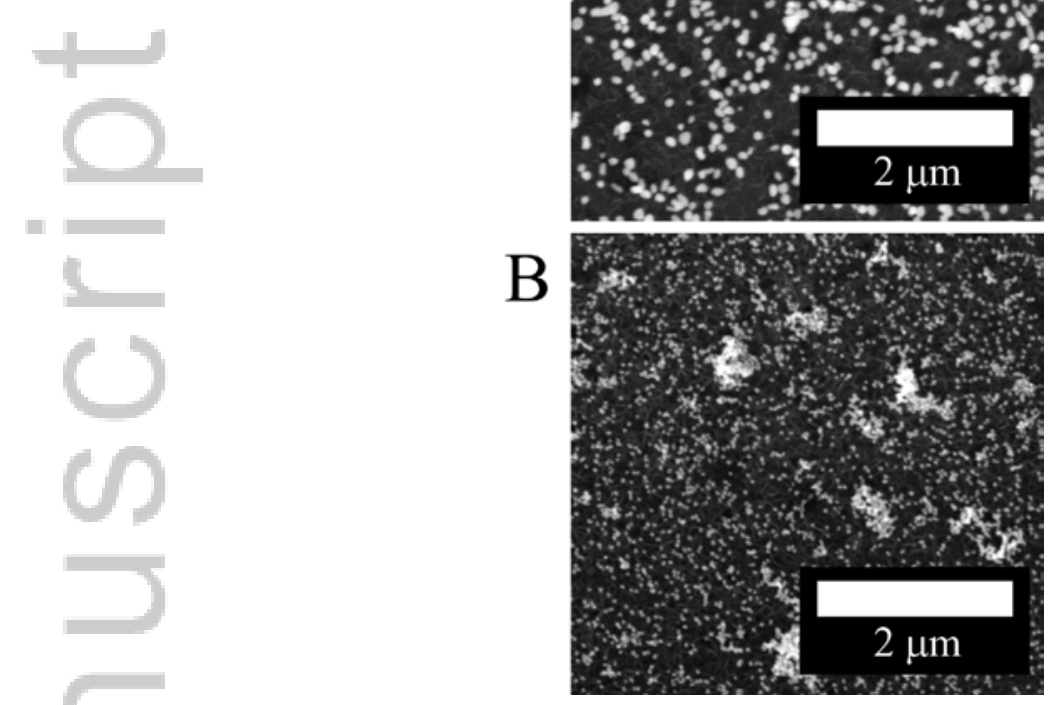

Figure 3. Self-assembly of A) $100 \mathrm{~nm}$ gold nanoparticles and B) $50 \mathrm{~nm}$ gold nanoparticles on APTMS functionalized WE43.

Nanoparticle self-assembly can exhibit noticeable variation, both sample-to-sample and also across the surface of a single sample. Sample to sample variation is evident in figure 2, and a variation across a sample surface is shown in figure 4. In figure 4, one area on the surface exhibited an isotropic pattern with evenly distributed nanoparticles, whereas another area contained significant particle clumping. It is not clear how to prevent this localized particle clumping. If particle clumping occurred, the sample was re-polished and the technique was applied again. There was approximately a $20 \%$ success rate producing samples on which particle clumping did not significantly occur. In figure 2, where clumping did not occur, the assembly kinetics varied greatly from sample to sample, even between specimens of the same alloy. Each surface represents the time required to achieve a similar density of particles, and these times were not consistent between the alloys and between tests. Sometimes, a dense nanoparticle array would appear after 16 hours, whereas a 120 hour soak time was needed on other samples, with 
no trend exhibited between tests..Although the technique was successful for some specimens, more work is needed to improve the consistency of the self-assembly process. Previous work has suggested that contamination on the surface possibly caused particle clumping [12]. From this study, it is suspected that the problem is obtaining an even silane layer on the surface. Removal of the substrate from the silane solution resulted in a rainbow sheen on the surface, suggesting that the silane layer thickness varies. It is suspected that a variance in silane thickness may result in differing particle densities and particle clumping. Furthermore, it was seen that adding $\mathrm{NaOH}$ to the nanoparticles can still result in proper self-assembly, despite the fact that the charge of the amine group switches once the isoelectric point is reached and should lead to electrostatic repulsion between the nanoparticles and the substrate APTMS layer. Further understanding of the chemistry may be needed to improve consistency.

Despite the consistency issues, this technique is a promising solution for patterning magnesium and other corrosion susceptible materials. The key lies in controlling corrosion during the long soak time in the nanoparticle suspension. In theory, established corrosion inhibitors may be added to the nanoparticle solution for any corrosion-susceptible material (assuming those inhibitors do not break down the nanoparticles) and allow for nanoparticle selfassembly on a wide range substrates.

This article is protected by copyright. All rights reserved. 

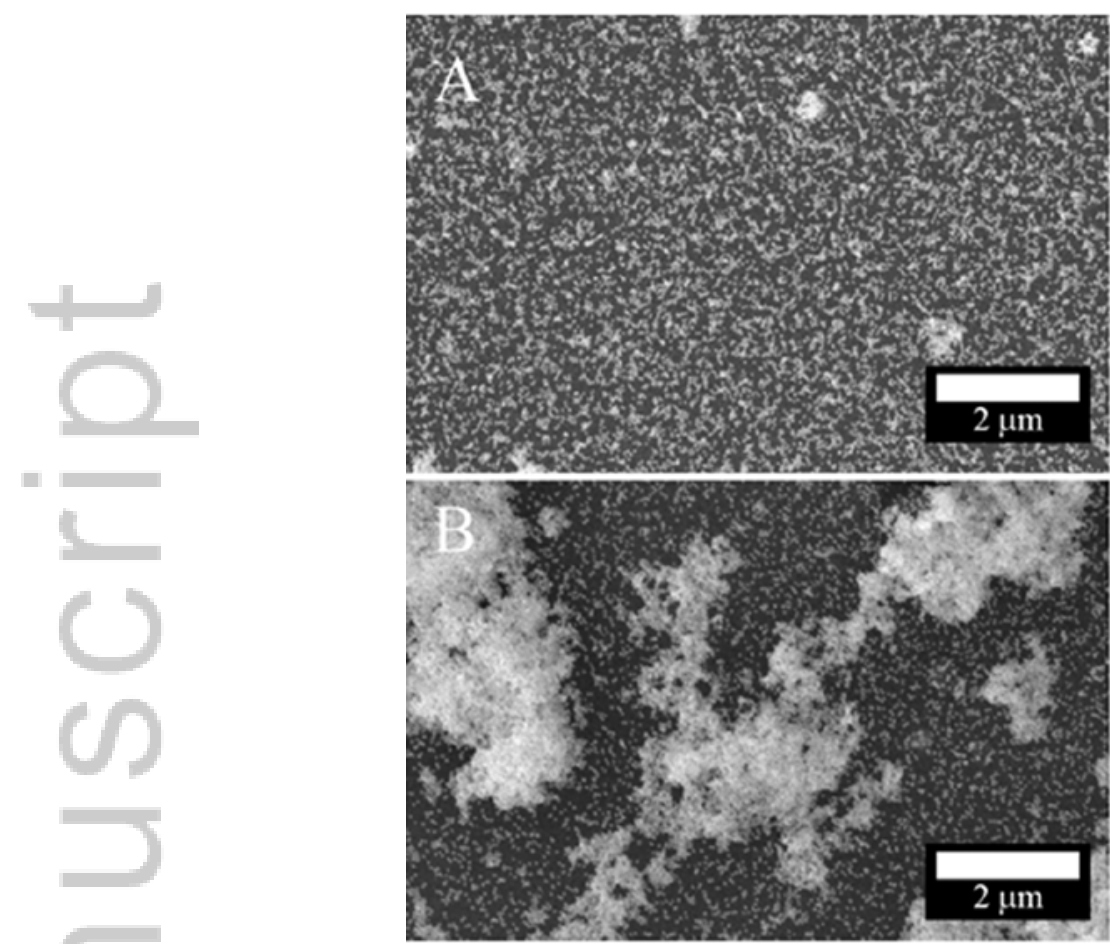

Figure 4. Nanoparticle patterns across the sample surface of magnesium alloy WE43, using MPTMS as a silane coupling agent and immersed in basic 50nm gold nanoparticles for 16 hours. A) An area where particle distribution is evenly dispersed and isotropic. B) A different area of the same sample showing significant and unwanted particle clumping. This particle clumping may be due to uneven silane layer deposition and occurred in $\sim 80 \%$ of specimens.

\subsection{In-situ Mechanical Testing}

Figure 5A shows a successful self-assembly of $100 \mathrm{~nm}$ nanoparticles on the magnesium alloy WE43 for use as a speckle pattern during scanning electron microscopy combined with digital image correlation. The acid etch used in this study aggressively attacks the grain boundaries, resulting in a deep grain boundary etch that can be seen beneath the speckle pattern and is ideal for demonstration purposes of this technique. In subsequent studies of the microstructural response to plastic deformation, a less aggressive etch that does not attack grain boundaries preferentially is used. The speckle pattern enables the quantification of strain at high 
magnification using SEM-DIC, as shown in Figure 5C, where there is strong sub-grain heterogeneity in strain distribution with strain tending to localize at grain boundaries. This localization is partly due to the stress concentration at the grain boundaries from the etchant.

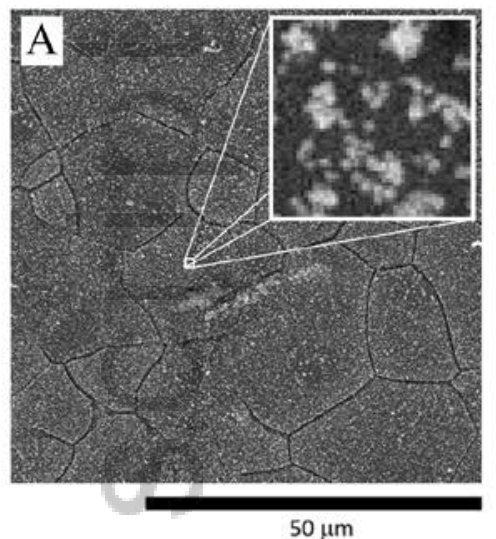

$50 \mu \mathrm{m}$

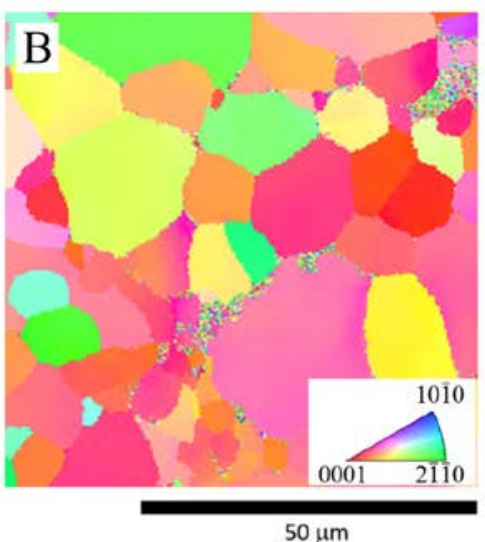

$50 \mu \mathrm{m}$

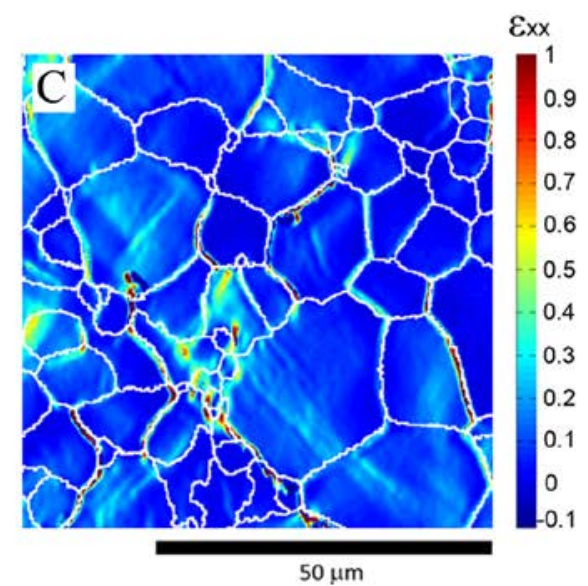

$50 \mu \mathrm{m}$

Figure 5. SEM-DIC results for an in-situ test conducted on the Mg alloy WE43: A) $100 \mathrm{~nm}$ gold nanoparticles self-assembled on the surface, by controlling the $\mathbf{p H}$ basicity, to serve as a speckle pattern. Magnified is the subset (size 51) used for DIC, where the width of a pixel in the subset is $33.2 \mathrm{~nm}$. Each nanoparticle is roughly $3 \times 3$ pixels for ideal DIC results; B) EBSD orientation map of the underlying microstructure; C) Full-field strain map during global plastic deformation, showing strong sub-grain heterogeneity in strain distribution with strain tending to localize at grain boundaries. Spatial resolution of the strain calculation is approximately 0.85 microns based on the subset size.

\section{Summary}

The successful self-assembly of gold nanoparticles on pure magnesium and three of its alloys was achieved through a passivated corrosion reaction with a gold nanoparticle suspension. To the best of the authors' knowledge, this is the first self-assembly of nanoparticles on magnesium that has been reported. This technique is amendable to other corrosion-susceptible materials if corrosion can be prevented during the long immersion in the nanoparticle suspension via $\mathrm{pH}$ adjustment or the addition of other established corrosion inhibitors. The proposed approach is inexpensive, provides dense coverage, and can be easily scaled by adjusting the size of the nanoparticles. 


\section{Acknowledgements}

This work was supported by the U.S. Department of Energy, Office of Basic Energy Sciences, Division of Materials Sciences and Engineering under Award \#DE-SC0008637 as part of the Center for PRedictive Integrated Structural Materials Science (PRISMS) at the University of Michigan. We gratefully acknowledge John Allison (University of Michigan) for helpful discussions and insight, and Robert Kubic (General Motors Research) for his assistance and advice on polishing magnesium alloys.

\section{References}

1. Shipway A, Katz E, Willner I "Nanoparticle Arrays on Surfaces for Electronic, Optical, and Sensor Applications," Chemphyschem 1:18-52. (2000).

2. Weissman J, Sunkara H, Tse A, Asher S "Thermally Switchable Periodicities and Diffraction from Mesoscopically Ordered Materials," Science 274:959-60. (1996).

3. Musick M, Peña D, Botsko S, McEvoy TM, Richardson JN, Natan J "Electrochemical Properties of Colloidal Au-Based Surfaces: Multilayer Assemblies and Seeded Colloid Films," Langmuir 15:844-850. (1999).

4. Green S, Stokes J, Hostetler M, Pietron J, Murray RW "Three-Dimensional Monolayers: Nanometer-Sized Electrodes of Alkanethiolate-Stabilized Gold Cluster Molecules," J Phys Chem B 101:2663-2668. (1997).

5. Sato T, Ahmed H, Brown D, Johnson BFG "Single electron transistor using a molecularly linked gold colloidal particle chain," J Appl Phys 82:696-701. (1997).

This article is protected by copyright. All rights reserved. 
6. Klein DL, McEuen PL, Katari JEB, Roth R, Alivisatos AP "An approach to electrical studies of single nanocrystals," Appl Phys Lett 68:2574-2576. (1996).

7. Andres R, Bein T, Dorogi M, Feng S, Henderson JI, Kubiak CP, Mahoney W, Osifchin RG, Reifenberger R "“Coulomb Staircase" at Room Temperature in a Self-Assembled Molecular Nanostructure," Science 272:1323-1325. (1996).

8. Grabar KC, Allison KJ, Baker BE, Bright RM, Brown KR, Freeman RG, Fox AP, Keating CD, Musick MD, Natan MJ "Two-Dimensional Arrays of Colloidal Gold Particles: A Flexible Approach to Macroscopic Metal Surfaces," Langmuir 12:2353-2361. (1996).

9. Freeman RG, Grabar KC, Allison KJ, Bright RM, Davis JA, Guthrie AP, Hommer MB, Jackson MA, Smith PC, Walter DG, Natan MJ "Self-Assembled Metal Colloid Monolayers: An Approach to SERS Substrates," Science 267:1629-32. (1995).

10. Chumanov G, Sokolov K, Gregory BW, Cotton TM "Colloidal Metal Films as a Substrate for Surface-Enhanced Spectroscopy," J Phys Chem 99:9466-9471. (1995).

11. Grabar K, Freeman R, Hommer M, Natan M "Preparation and Characterization of Au Colloid Monolayers," Anal Chem 67:1217-1225. (1995).

12. Kammers AD, Daly S "Self-Assembled Nanoparticle Surface Patterning for Improved Digital Image Correlation in a Scanning Electron Microscope," Exp Mech 53:1333-1341. (2013).

This article is protected by copyright. All rights reserved. 
13. Scott AF, Gray-Munro JE, Shepherd JL "Influence of coating bath chemistry on the deposition of 3-mercaptopropyl trimethoxysilane films deposited on magnesium alloy," J Colloid Interface Sci 343:474-83. (2010).

14. Zucchi F, Frignani a., Grassi V, et al. "Organo-silane coatings for AZ31 magnesium alloy corrosion protection," Mater Chem Phys 110:263-268. (2008).

15. Zucchi F, Grassi V, Frignani A, Monticelli C, Trabanelli G "Influence of a silane treatment on the corrosion resistance of a WE43 magnesium alloy," Surf Coatings Technol 200:41364143. (2006).

16. Scott A, Gray-Munro JE "The surface chemistry of 3-mercaptopropyltrimethoxysilane films deposited on magnesium alloy AZ91," Thin Solid Films 517:6809-6816. (2009).

17. Ostrovsky I "Treatment for improved magnesium surface corrosion-resistance," US Patent 7,011,719. (2006).

18. Kim J, Wong KC, Wong PC, Kulinich SA, Metson JB, Mitchell KAR "Characterization of AZ91 magnesium alloy and organosilane adsorption on its surface," Appl Surf Sci 253:41974207. (2007).

19. Montemor MF, Ferreira MGS "Electrochemical study of modified bis-[triethoxysilylpropyl] tetrasulfide silane films applied on the AZ31 Mg alloy," Electrochim Acta 52:7486-7495. (2007).

20. Pourbaix M "Atlas of Electrochemical Equilibria in Aqueous Solutions, 2nd Englis," 139. (1974).

This article is protected by copyright. All rights reserved. 
21. Kammers a D, Daly S (2011) Small-scale patterning methods for digital image correlation under scanning electron microscopy. Meas Sci Technol 22:125501. doi: 10.1088/0957$0233 / 22 / 12 / 125501$

22. Sutton MA, Li N, Garcia D, et al. (2006) Metrology in a scanning electron microscope: theoretical developments and experimental validation. Meas Sci Technol 17:2613-2622. doi: 10.1088/0957-0233/17/10/012

23. Sutton MA, Li N, Joy DC, et al. (2007) Scanning Electron Microscopy for Quantitative Small and Large Deformation Measurements Part I: SEM Imaging at Magnifications from 200 to 10,000. Exp Mech 47:775-787. doi: 10.1007/s11340-007-9042-z

24. Sutton MA, Li N, Garcia D, et al. (2007) Scanning Electron Microscopy for Quantitative Small and Large Deformation Measurements Part II: Experimental Validation for Magnifications from 200 to 10,000. Exp Mech 47:789-804. doi: 10.1007/s11340-007-9041-0

25. Kimiecik M, Jones JW, Daly S (2013) Quantitative Studies of microstructural phase transformation in Nickel-Titanium. Mater Lett 95:25-29. doi: 10.1016/j.matlet.2012.12.063

26. Pan G, Schaefer DW "Morphology and water-barrier properties of silane films on aluminum and silicon," Thin Solid Films 503:259-267. (2006).

27. Li G, Wang X, Li A, Wang W, Zheng L "Fabrication and adhesive properties of thin organosilane films coated on low carbon steel substrates," Surf Coatings Technol 201:95719578. (2007).

28. Frens $G$ "Controlled nucleation for the regulation of the particle size in monodisperse gold suspensions," Nature 241:20-22. (1973).

This article is protected by copyright. All rights reserved. 


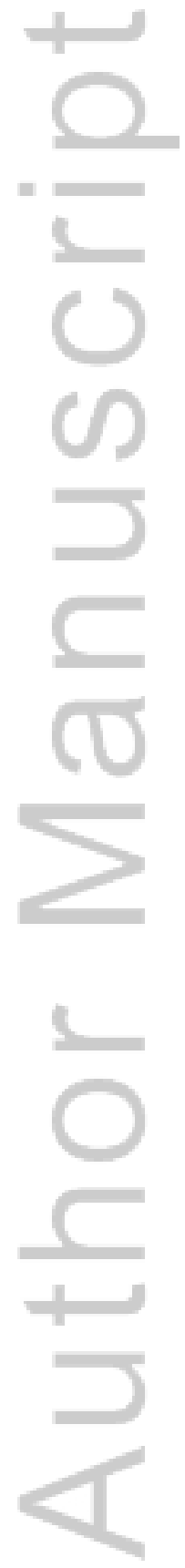

This article is protected by copyright. All rights reserved. 


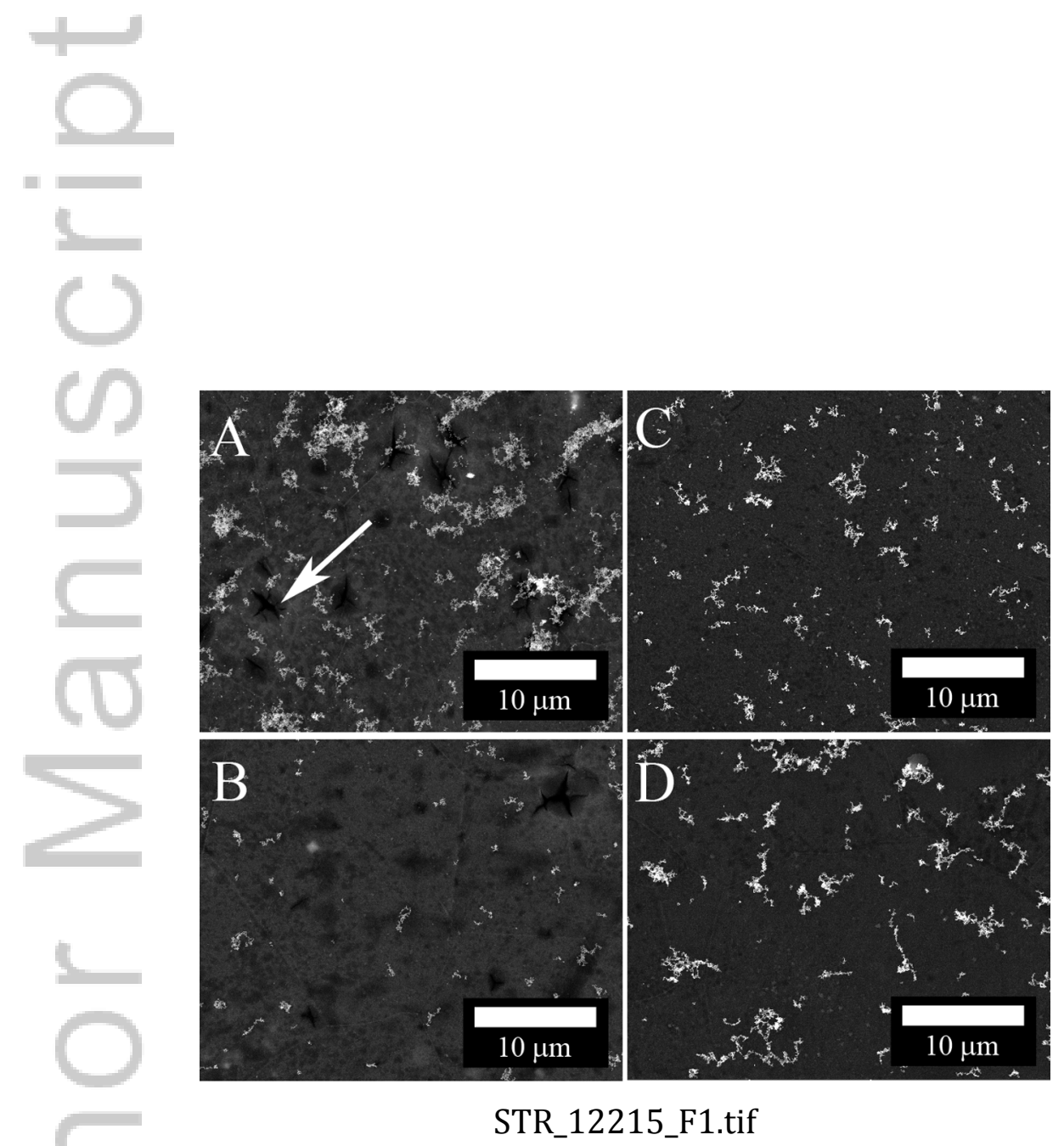

This article is protected by copyright. All rights reserved. 


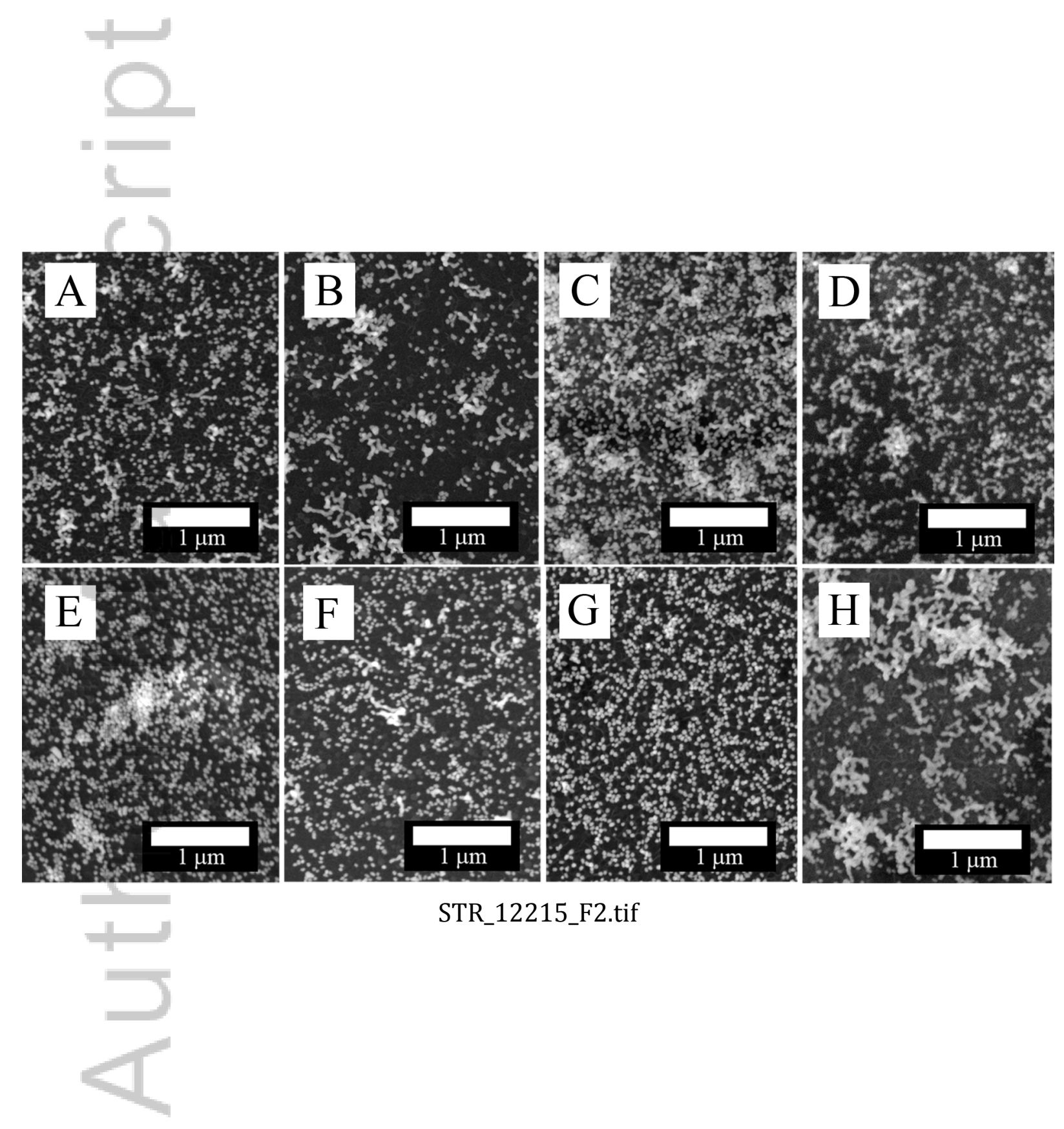

This article is protected by copyright. All rights reserved. 

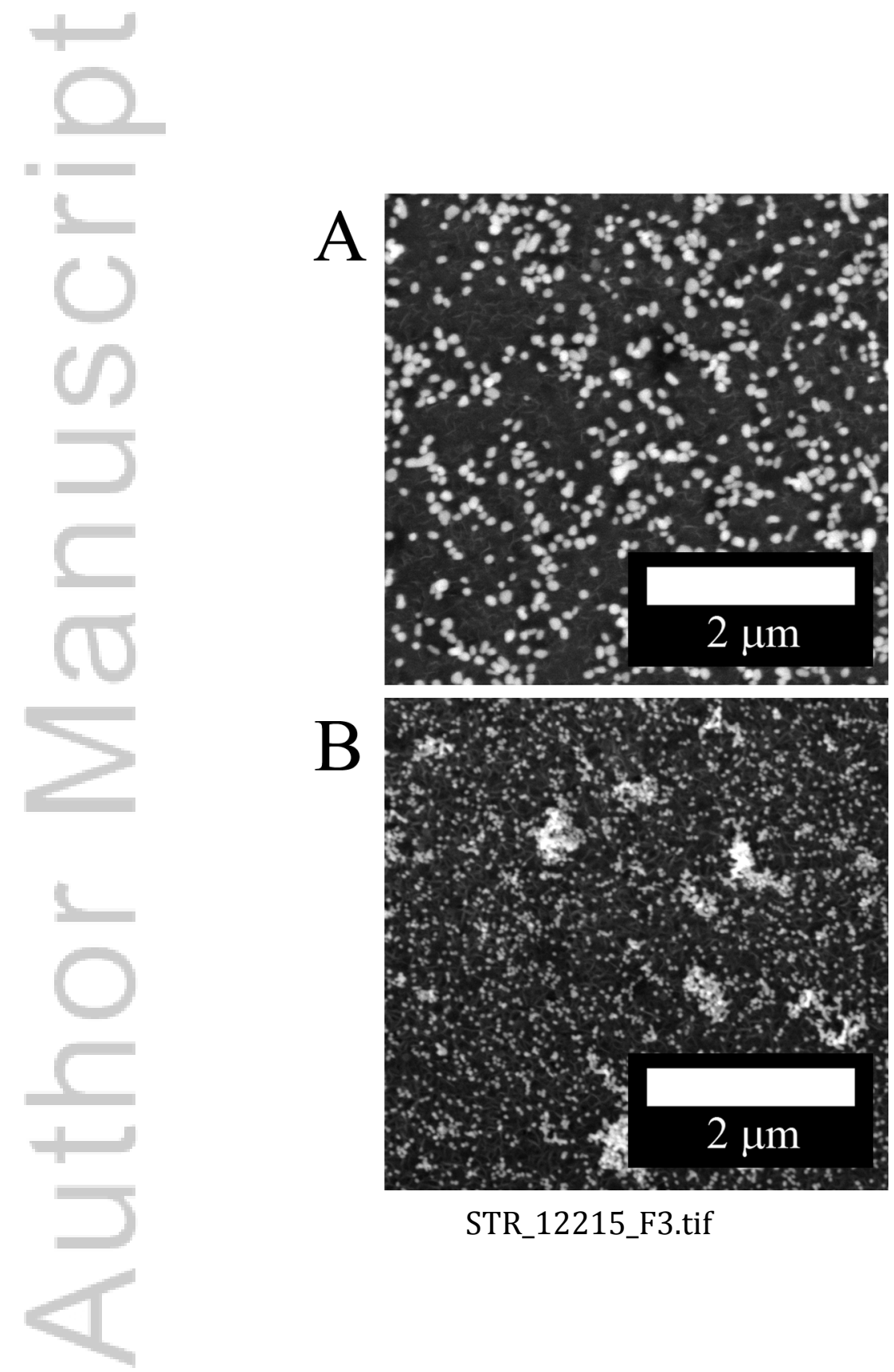

STR_12215_F3.tif

This article is protected by copyright. All rights reserved. 

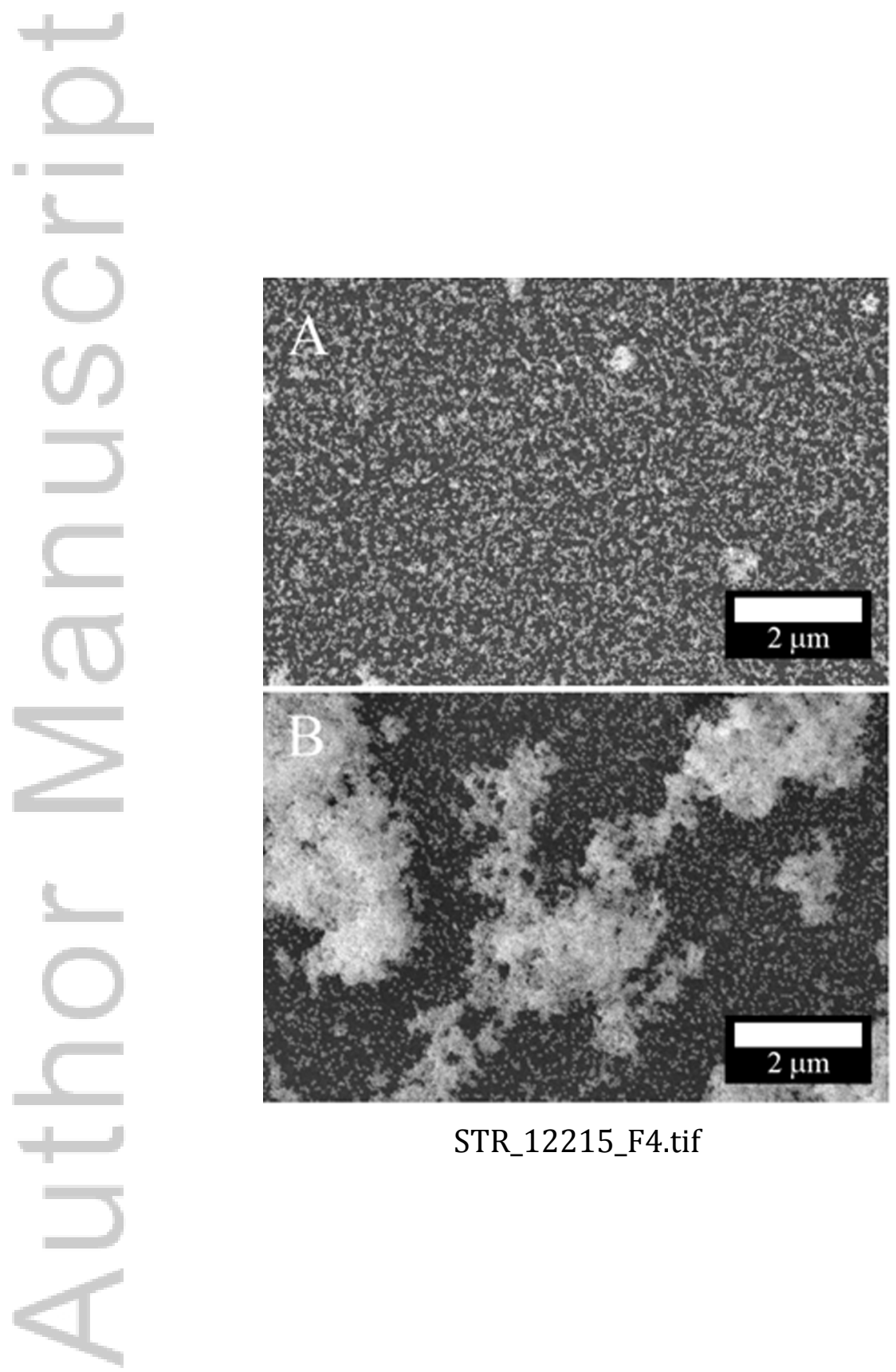

STR_12215_F4.tif

This article is protected by copyright. All rights reserved. 


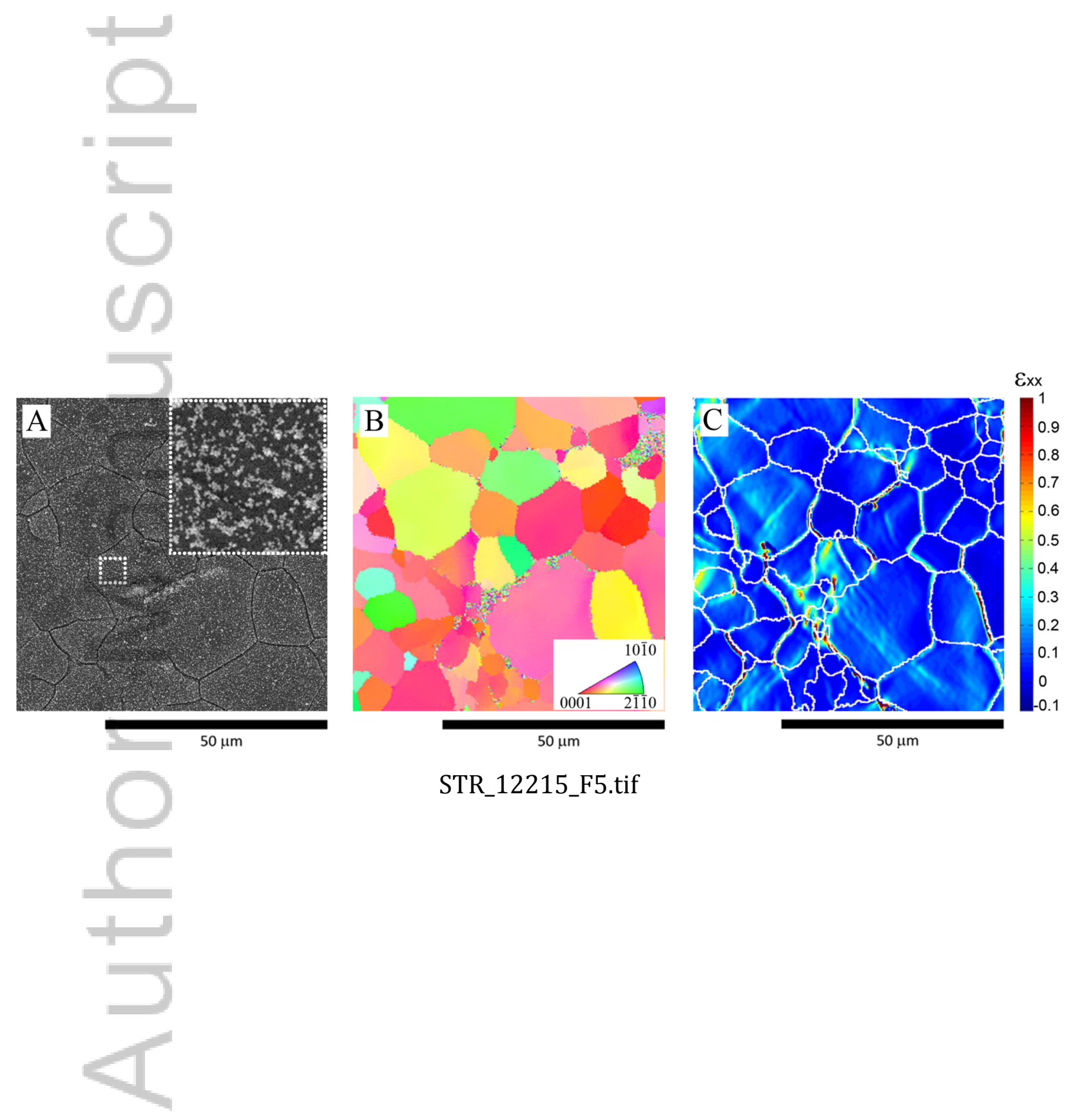

This article is protected by copyright. All rights reserved. 